\title{
Part I: An Introduction to Transport and Development
}

\section{Chapter 1}

\section{Introduction}

Robin Hickman, Moshe Givoni, David Bonilla, David Banister

\section{Understanding the linkages between transport and development}

Arthur Miller's (1949, p. 12) famous prose on the diffidence of life in suburbia nicely encapsulates the focus of this edited collection:

Linda: We should've bought the land next door.

Willy: The street is lined with cars. There's not a breath of fresh air in the neighbourhood. The grass don't grow anymore, you can't raise a carrot in the backyard. They should've had a law against apartment houses. Remember those two beautiful elm trees out there? When I and Biff hung the swing between them?

Linda: Yeah, like being a million miles from the city.

There appears to be some evident relationships between urban development and travel, between transport investment and the built form and wider impacts it helps to shape, in the individual and cultural attitudes to this and from this, and in the modifications to these relationships over time. This area of research - the changing nexus between transport and development - has been examined and debated since at least the late 1800s, from the building of the early railway systems in Europe; through to the development of the major highway and motorway networks in the United States and Europe from the 1920s onwards, and continuing in many contexts; as major infrastructure projects are considered and carefully examined as to likely developmental impacts; and more recently as the psychological and cultural factors surrounding travel are examined alongside infrastructural and developmental aspects. Often it seems the development form follows the transport investment, from the Victorian suburbs of London built around the early railway and Underground lines; to the dispersed suburbia following the newly developed highway networks in the United States. But, the causality is rarely in one direction, and often the development form helps shape the transport infrastructure investments: the dispersed city requiring more highway investments, the compact centres requiring public transport, walking and cycling improvements. The linkages are often complex, sometimes easy to understand, and on occasions difficult and subtle. They are most always debated. It is this debate which is the focus of the International Handbook on Transport and Development.

The idea for the edited collection arose from various conversations that the Editors had whilst researching at the Transport Studies Unit, University of Oxford. It seemed that we all tackled the same broad topic from different directions - as urban planners interested in what transport investments worked 'best' for the city, and how urban planning might help generate greater sustainability in travel behaviours; as economists interested in the impacts that infrastructure investment might have on the economy and wider societal issues; and all 
of us were interested in the psychology and sociology of travel, and what role this might play in urban development. The book is thus organised in three main sections, and these are outlined below.

\section{Part II: Urban structure and travel}

Part II presents 13 chapters, each presenting research on the built environment and its relationship with travel. The chapters exploring the main debates, such as the key built form variables, the influence of urban structure at different scales, over time; the locational and contextual dimensions; and the roles of attitudes, including the concept of 'self selection' (the choice of residential, and indeed employment and other activities, based on an individual's travel and other attitudinal preferences).

The first chapter, from Philip Stoker, Susan Petheram and Reid Ewing, opens with an overview of the topic, arguing that the built environment is an important factor in travel behaviour, with the relationship evident at different scales, such as the regional (macro) and neighbourhood (mezzo) scales. Measures of sprawl are defined and discussed, with significant relationships associated with vehicle miles travelled (VMT) and mode share. Elasticities are then derived from the most common built environment factors - using the '3 Ds' (density, diversity and design) and '5 Ds' typologies (destination accessibility and distance to transit). Individual elasticities are fairly small, but combined effects can be quite large - hence the case is made for shaping the built environment to help reduce private motor car-based travel.

Peter Newman and Jeff Kenworthy present the patterns of transport carbon dioxide (CO2) emissions and energy consumption in cities globally. They discuss the large variation in transport emissions between cities, such as 100kgCO2 in Ho Chi Minh City, 3,000 kgCO2 in New York, rising to 7,500 kgCO2 in Atlanta; and the varied mode shares for the private car, public transport and non-motorised transport contributing to this. The relationships between transport and built environment characteristics are then explored, again with great difference in city densities, such as Ho Chi Minh City with over 350 persons per hectare and Atlanta at a density of 6 persons per hectare. Equity is brought out as an important issue, with different contexts developing very different transport systems and urban forms, resulting in a huge variation in emissions and energy consumption.

Peter Headicar, using a case study of Oxfordshire (UK), considers the relationships between homes, jobs and commuting, arguing that the strategic dimension of commuting outside the home settlement is overlooked in policy-making - and that there is a strong locational element within the urban structure and travel relationship. A lack of workplaces in the surrounding area and poor public transport availability means that some neighbourhoods have higher than average public transport mode shares (such as Bicester); whereas others with more local employment opportunities and better public transport connections have much greater usage of public transport (Didcot). The spreading of housing allocations across these different settlements produces very uneven travel outcomes.

Robin Hickman and David Banister examine new households in Surrey (UK), using longitudinal analysis to assess the temporal relationships between the built environment, 
socio-economic characteristics and the commute to work. A residential typology is developed: with 'stayers' (households remaining over the three year survey time period), 'outmovers' (those moving away from the original residence), and 'inmovers' (those moving in). The stayers experience the least transport energy consumption relative to the other cohorts - 9\% lower than the sample average in 1998. However, energy consumption increases over time, by 3\% from 1998-2001. This reflects trends which move in different directions: journey distance and journey time reduce, yet car mode share increases. A number of variables are significantly correlated with transport energy consumption, such as residential population density, distance from London, public transport accessibility and household income. There are important changes over the period 1998-2001, such as the lower residential densities increasing their transport energy consumption, and the higher densities reducing their transport energy consumption. Locational and temporal issues thus seem to be a critical feature in the urban structure and travel relationship.

Peter Gordon and Bumsoo Lee assess city size, spatial organisation, and commuting and non-commuting trends in US metropolitan areas. They ask whether the impacts of the built environment on travel are large enough to justify land use policies to help influence travel behaviours. The analysis seeks to understand whether metropolitan level spatial restructuring, towards more dispersed forms, is linked to reduced travel times. Average commuting times appear to rise with metropolitan size, but as cities continue to increase in size and sprawl, the commuting time and non-work travel remain fairly static. The locations of homes, workplaces and other activities appear to be chosen for a variety of reasons, including some level of 'mutual accessibility'.

Marcial Echenique and Alastair Donald analyse commuting and non-work travel in Greater London and the South East of the UK, considering the role of mixed use development and density in reducing travel distance and private car mode share. Residential, employment areas and more mixed residential and employment areas are compared in terms of their travel patterns, including inflows, outflows and total flows. The areas with high employment concentrations attract longer average trip distances for the journey to work (total flows), but there is little difference between suburban and mixed residential/employment areas in terms of trip distance. There is a similar trend for nonwork trips and also for mode share - only the high employment concentrations demonstrate a significant public transport mode share. Correlations between density and private car usage are also weak, with the higher employment densities leading to longer trip distances.

Petter Naess gives a more positive view on the urban structure and travel relationships, using case studies of Hangzhou (China) and Copenhagen (Denmark). The case study contexts are of course very different; for example, car ownership and mobility levels in Copenhagen are much greater than in Hangzhou. The location relative to the main centre of the urban area appears to be the most important urban characteristic. An important point is made: that considering the self selection effect may help underestimate the influence of the built environment on travel. For example, inner cities residents who do not value proximity to public transport, employment or shopping opportunities as criteria for locational choice, travel much less by car than suburban respondents who do value these criteria (the dissonance factor). If attitudes were more important than location, we might expect the reverse effect. Travel distances seem to depend more on the location of the dwelling to the 
main concentration of activities, but are modified by factors such as specialised job skills, leisure interests, 'exclusive’ cultural tastes, time availability, etc.

Carey Curtis considers the role of public transport accessibility, alongside changes to the built form, in achieving greater sustainability in travel. A GIS-based accessibility modelling tool (SNAMUTS) is developed and applied in Perth (Australia), assessing centrality, impacts of network modifications, catchment, speed and network connectivity. Activity centres around public transport nodes are then developed - the tool helping to consider which centres should be developed at the regional and local levels and where the public transport investment should be prioritised. Network connectivity and improved service frequencies are seen as critical factors in gaining higher public transport mode shares.

Jason Cao examines the role of attitudes in the relationship between neighbourhood type and travel (vehicle miles driven), using a case study of Northern California (US). He considers whether people living in walkable neighbourhoods walk more because the built environment 'invites' them to do so, or whether people who like to walk choose these types of neighbourhoods, i.e. he explores the role of the self selection effect and potential directions of causality. A theoretical model is developed to assess the possible interactions: attitudes as antecedent, intervening, or of little or no importance. In reality, there are likely to be multiple directions of causality and, in the North Californian data, the impact of neighbourhood type accounts for $13 \%$ of average driving distance after controlling for attitudinal aspects.

Bert Van Wee and Patricia Mokhtarian also discuss the role of attitudes, in terms of residential self selection and travel, arguing that there is heterogeneity between respondents that is not fully captured by socioeconomic and demographic variables, and consequently there is always a risk of self-selection based on those other (attitudinal) variables. A number of methodologies that have been used to account for residential self-selection are reviewed. The measurement of attitudes and the relevance of attitude-related self-selection for travel behaviour are discussed, distinguishing between residential choice, other spatial choices (such as work location) and non-spatial choices relevant for travel behaviour. It is suggested that 'perfectly' measuring attitudes might come at a cost of accuracy in measuring travel behaviour or a lower response rate in surveys.

Kevin Krizek, Ahmed El-Geneidy and Ryan Wilson use data from the Twin Cities (Minnesota, US) to analyse the consistency of preferences for neighbourhood types among intra-county movers. The analysis employs factor and cluster analysis to define eight neighbourhood types and finds 54 percent of respondents moving to new neighbourhoods embodied similar features to their previous neighbourhood. The determinants of moves within neighbourhood types are also discussed, together with implications for land use and transportation policy.

Susan Handy examines the evidence on the impact of community design on active travel and finds that various functional elements, covering functional, aesthetic and natural dimensions, are important in influencing the use of walking and cycling. She also discusses the practical implications - asking what policies, investments, or mechanisms can 
communities use to create environments that are more supportive of walking and bicycling?

Wesley Marshall, Norman Garrick and Stephen Marshall conclude this section by considering what makes a good street network. The characteristics of street networks are examined relative to the amount of driving by private car, the tendency to walk or bike, and levels of community safety and health. A dataset is collected for 24 Californian cities with populations ranging from 30,000 to around 100,000 residents. The analysis asks whether the three fundamental characteristics of street design - street connectivity, street network density and street patterns - are associated with residents driving fewer miles and also walking and cycling more.

\section{Part III: Transport and spatial impacts}

In Part III, the book shifts focus to examine the varied spatial impacts of transport investments. 16 chapters are presented, with the analysis exploring the debates in the literature from the standpoints of different modes, types of 'impact', and empirical approach. We can see that most research studies, in this book and in the wider literature, are ex-ante in nature (before the event), and there is little analysis that is ex-post (after the event). Much of the research emphasises, explicitly or implicitly, that 'development' and 'impact' is perceived mainly in economic terms. This is challenged towards the end of Part III, and continues into Part IV, where a much wider perspective of transport and development is taken. These areas, of course, reflect many of the key debates within the topic of transport and development, i.e. what is meant by development and how might this be effectively measured?

The first chapter, from Piet Rietveld and Frank Bruinsma, gives a brief historical overview of transport as a main driving force in urban development, and revisits the theory on how transport (investments) could affect spatial change and economic development. They highlight the challenge of determining the spatial scale at which impacts are measured, since, in most cases, what might be a positive development impact at a certain (local) scale is potentially a redistribution impact when looked at a wider scale (regional or national). The impacts from transport investment can be varied and are likely to be both positive and negative at the same time in different locations. This results in large difficulties in empirical analysis and many varying results in the literature depending on the assumptions taken in the research.

Michael Iacono and David Levinson examine the basic methods of evaluating the impacts of transport investment, such as the common use of Cost-Benefit analysis (CBA) and the limitation of such approaches, for example when it is obvious that the impacts will not be confined to the immediate area around the project. They suggest tools used in regional economic analysis should be applied. Changes in land values may also better capture the impacts of transport investment to also account for induced demand which may, in some instances, be seen as a negative impact as it contributes to congestion and the erosion of the benefits from investments.

Torben Holvad and Steen Leleur review the theoretical and empirical evidence regarding the linkages between transport projects and the economy. They consider the possible 
solutions concerning how the wider economic impacts can be integrated into project appraisal, notably through cost-benefit analysis. The role of computable general equilibrium (CGE) modelling is also highlighted to provide information about the effects of improved accessibility on the economy.

David Hensher and Zheng Li look at urban freight distribution as a critical part of the city economy, viewing the biggest challenge facing urban freight distribution as traffic congestion on roads and at key transfer locations such as ports and consolidation terminals. The role of government is seen as important to articulate and facilitate the linkages between short-term and long-term policies on land use planning, environmental externalities and the transport task. Within the urban environment, a strategy is required for the location of rail hubs servicing the road-rail interface, focused on integrated multimodal service provision.

Eran Feitelson and Orit Rotem-Mindali consider the role of public transport investments in metropolitan areas and ask to what extent there is an effect in the car-dominated metropolitan structure. They briefly review the historical timeline of rail and suburban development, and comment on the current empirical difficulties in assessing the impacts of Light Rapid Transit (LRT) and Bus Rapid Transit (BRT) schemes in a car-dominated landscape. The evidence of impacts is mixed, with little impact at the macro scale, and impacts mostly occurring at the micro level, in close proximity to stations. Any effects, however, are determined by local economic trends, the socio-economic structure of the area, the associated planning strategy, the existing built stock, and the physical context around stations. Hence, the micro effects vary between cities, different parts of the city, and between different sections of the LRT or BRT corridor, and by different types of activity.

Chia-Lin Chen and Peter Hall present a comparative analysis of the wider impacts of High Speed Trains (HST) in Britain and France, asking whether, to what extent, and in what ways, HSTs could reduce inter- and intra-regional inequality. A review of the literature finds that the contradictory evidence is often due to the specificities of the context and that understanding the interregional competition between cities is particularly difficult, and poorly understood, as many of the benefits are relative in nature. Qualitative in-depth interviews and policy analysis offer insights into the wider spatial-economic outcomes. A number of critical factors are suggested for the differential effects, including the national political economy (the perception and exploitation of the HST opportunity, macro economy), governance approaches (level of devolved decision-making, resource allocation, and financial levers available), planning approach (including level of integration between development and transport investment), local political leadership, and city type (local economy, employment sectors, city attractiveness and competition). The contrast between the UK's market-led approach and the French interventionist approach is examined and proves highly instructive, with very different impacts following the transport investments.

Peter Jones provides a rare example of ex-post analysis of transport investment, reporting on an in-depth study of the wider impacts of the Jubilee Line Extension in East London (UK). The JLE is an interesting example, built despite a low cost-benefit ratio, largely for the aspiration of supporting regeneration in east London. The real challenge in such analysis is not only to measure and quantify the impacts that have followed, but to estimate the counterfactual (what would have happened without the project) and to attribute causation to the transport intervention. A range of impacts are examined, including: 
transport and accessibility changes; residential and commercial development, land value; employment and changes in the economy; and impacts on incumbent and migrant residents and their travel patterns. The evidence suggests that the JLE has raised land values and property prices in the surrounding area and has stimulated faster development than might otherwise have been expected. But, there was little positive impact on employment among the incumbent populations, either in terms of higher levels or in the character of employment (occupation and industry); instead, aggregate benefits are largely the result of the different profile arising from in-movers. A long lead time is required to assess many impacts, e.g. several decades might be required to allow the full effects of the project on land use patterns.

Lucia Mejia-Dorantes uses a spatial-statistical approach with micro-level data to evaluate the effects of Madrid's (Spain) Metrosur expansion on retail businesses location patterns. The analysis uses point pattern density surfaces to show where firms have increased or decreased in activity. It is argued that the increase in accessibility brought about by the new Metro line is not associated with an increase in retail activity around the station areas, though the probability of location of economic activity is greater in Getafe and Leganes relative to Fuenlabrada. Much of this may be due to the location of Fuenlabrada, which is the furthest from the centre of Madrid.

Dario Hildago and Juan Carlos Muñoz provide a global overview of the development of Bus Rapid Transit (BRT) and Bus of High Level of Service (BHLS), rapidly emerging in practice in South America and Asia, with more limited experience in Africa, North America and Europe. The commentary includes the well-recounted upgrade of busways in Curitiba, Brazil, to fully specified BRT in 1982, and the implementation of TransMilenio in Bogotá, Colombia, in 2000; and also the wider global experience from cities such Jakarta and Guangzhou. In 2014, there were around 180 cities with BRT or similar types of systems globally, serving more than 31.5 million passengers per day, with 152 cities developing systems since 2001 - an incredible growth in the last decade or so. The transport benefits of the systems are made clear - in terms of reliability, comfort and low cost urban mobility. There are also impacts in developmental terms, with some studies citing development pattern and land value changes, though the evidence here is much less, and the causal chains often unclear or indirect.

Andy Goetz examines the growth in air passenger and cargo transport as a major element of global commerce, including air-based tourism, trade, logistics, and producer services. He considers the developmental impact of Denver international airport, reflecting the wider aspiration of many cities to develop the 'aerotropolis' model of new poles of economic activities and development around their airports. Thus airports not only connect cities and provide accessibility to markets, placing them on the global map; they can also become hubs for new city development, with enlarged agglomeration economies. While this impact is noticeable in the many expanding aerotropolises, and is generally viewed positively in economic terms, there are major concerns over the environmental sustainability of these airport cities, and these problems have yet to be resolved.

Chantal Cantarelli and Bent Flyvbjerg consider the decision-making process for major infrastructure projects, examining the high level of 'misinformation' concerning the estimation of costs and benefits in the appraisal of projects. They discuss the problems 
involved with this process of misinformation and the potential reasons for this happening. They examine how mega-project performance, in terms of the accuracy of the cost forecast, is influenced by project ownership (with the private or the public sector as promoters). They conclude that ownership is not a significant issue in project performance, and that there is little evidence that private projects perform better than public ones. A case study of the HSL-South railway line in the Netherlands demonstrates that the contracting strategy and the amount of private financing are better determinants of project performance. Again, there is seen to be a relative scarcity of ex-post analysis, with economic and wider dimensions, for transport investments.

The issue of externalities, and mainly those related to congestion, are central in the chapter by Jan Anne Annema, who considers how effective the various road pricing schemes are in 'reducing' congestion and thus can alleviate some of the negative impacts of investing in road infrastructure. The various international studies of road pricing schemes are compared, with a marked difference in results demonstrated according to context and methodological approach. Experience in the Netherlands is then examined, and despite the apparent effectiveness of some the potential pricing schemes (some more than others), the long and difficult political struggle with road pricing in the Netherlands and the accompanying controversy has still not resulted in implementation of any of the potential approaches. This angle in the debate on the spatial development impacts of transport investments connects back to the first chapter in the section, where Piet Rietveld and Frank Bruinsma suggest there is evidence that political considerations, such as the desire to be re-elected, can be a main driving force behind investment decisions.

Gordon Stokes widens the consideration of 'impacts' from transport, examining the relationship between travel behaviour and poverty, and in particular argues that low incomes and poor accessibility can lead to disproportionate spending on transport to access basic services, or lead to suppression of some trips. He notes that low income people, on average, travel less than those on higher incomes, and that they are much less likely to have access to cars. However, the link between (lack of) transport and poverty is not straightforward to assess, since poverty is influenced by an array of factors. Nevertheless, there is evidence that poorer people in rural areas (and other areas without travel alternatives) suffer through reliance on cars when they have difficulty affording them. Accessibility planning is offered as an approach to help consider the equity dimension within transport; alongside more effective public transport provision; land use planning to ensure transport poverty is not 'built in' to lifestyles; and innovative means of car access, such as car clubs and car share schemes, for areas which remain with low public transport accessibility.

Susan Kenyon considers the role of transport in social development. The discourses of 'too little mobility' and 'too much mobility' are explored relative to their impacts on social well-being. A case study of access to education in the UK is used to demonstrate how important transport and mobility can be to participation and to the educational experience. It is argued that the link is sometimes so strong that transport must be considered as a social policy in some cases - with inadequate transport often acting as a barrier to the improvement of social well-being. 
Iqbal Hamiduddin reviews the impact of the car at the neighbourhood scale. First, the history of the Garden City Movement (UK), and competing approaches such as found in Radburn (New Jersey, US), are reviewed in terms of their treatment of the car and the design of the street. Second, case studies in Freiburg and Tübingen (Germany) are explored, including the use of mixed use development, pedestrian and cycling priority, high quality public realm and 'home zones', good public transport access, reduced car parking provision, and also the Baugruppe approach to development (community-designed housing), all of which encourage very strong community bonds within the neighbourhoods examined.

Karst Geurs and Derek Halden conclude the section with a review of accessibility planning, in theory and practice, in the Netherlands and UK. Accessibility can be measured in a number of ways, including location-based, person-based and utility-based measures. Various levels of disaggregation can also be employed, either spatially or by population cohort; and levels of accessibility can also be related to policy objectives, such as social goals. In practice, in the Netherlands, there has been a gradual move from using accessibility indicators covering the transport provider perspective (e.g. the transport performance of infrastructure links) to a 'transport user' perspective (e.g. travel time and delay). In the UK, accessibility indicators have become central to transport planning appraisal since the late 1990s, often as a means of measuring progress against social objectives such as regeneration. The choice of accessibility measures (and the manner in which the evidence is used) strongly affects the related strategies and investments and, consequently, the impacts of accessibility changes on the spatial economy and social change. Hence, as always, the empirical approach used in the research remains critical to results.

\section{Part IV: Wider dimensions in transport and development}

Part IV contains 14 chapters examining wider dimensions which may affect the transport and development relationship, as previously conceived. The chapters explore the wider non-physical context that influences mobility patterns, i.e. how society and culture might impact on travel; or changes in technology, such as e-commerce, may influence the need for travel. Each of these themes represent new analytical challenges to transport researchers. The chapters reveal research that intersects with economic, demographic and wider social concerns related to, mainly, personal travel. As with the previous sections, Part IV reveals the breadth of academic research within the transport and development field, covering transport geography, sociology, economics and wider disciplines.

The first chapter, from Ole B. Jensen, opens by highlighting that travel is more than a 'derived demand' - that there is more to travel than the 'journey from A to B'. He reviews the emerging research on mobilities, including features such as culture, affect, habits, norms and emotions; hence widening our understanding of the potential rationales for travel. This is compared to the more conventional standpoints within transport planning, of rational choice in movement, and reducing friction (in distance, time and cost). 'Staging mobilities' are discussed - the proposition that mobilities are staged from above in planning and regulation terms, and below from everyday life. The debate is thus widened greatly, to help us understand that there are built environment deterministic factors associated with travel, that travel has impacts spatially and over time - but also that there 
are greater psychological, sociological and cultural contexts to travel and, in addition, development.

Ellen Matthies and Christian Klöckner explore the phenomenon of habit in travel behaviour, arguing that 'car-fixation' is a possible explanation for the limited success in reducing car usage. Cognitive mechanisms for habitual behaviours are discussed, including possibilities of script-based and connectionist processes. Socialization processes (early influences, family, school, media and peer group) appear to contribute to car-fixation, and particular groups of car users are more prone to fixation than others (e.g. men more than women, those living in rural areas more than urban). Strategies for preventing and overcoming car fixation, drawing again from psychological models, are also proposed, including situational changes (e.g. moving home or employment location) or temporary interventions to break habitual use (e.g. free travel card for public transport).

Galit Cohen-Blankshtain examines the role of information and communication technologies (ICTs) and their potential for changing travel behaviours, including the substitution of physical travel, but also modification and generation. The 'death of distance' hypothesis is explored, with telecommuting replacing commuting and e-retailing replacing walk-in retailing. The potential conclusion is that ICT networks might play the same role in the twenty-first century that streets and highways played in the twentieth century - with ICTs changing the shape of the city similar to the private car in earlier years. However, the 'friction reducing' effects of ICTs are largely discounted, for two main reasons: ICTs are being introduced into the car dependent city and do not directly replace the role of the private car. In addition, different technologies tend to have varied effects on travel behaviour. For example, mobile phones tend to compliment face-to-face activities, whilst the Internet substitutes some physical activities. In recent years, the technologies have merged, hence the smartphone allows both functions. The relationships are hence complex and evolving over time.

Orit Rotem-Mindali develops an analysis of e-retailing (both business to consumer, b2c, and consumer to consumer, c2c) and its impact on travel. She considers the recent locational and organisational changes in retailing, from small retail stores in inner urban locations, to larger footprint out-of-town stores; and perhaps back again as fuel prices rise, e-retailing becomes more frequently used, and the out-of-town bulk shop becomes less popular. The travel behaviour implications are often complex and heavily dependent on the context. For example, the mode and trip distance of the 'original' shopping trip and any substitution activities are important to estimates of change in transport energy consumption. The take up of e-retailing is also heavily dependent on the type of product and consumer; indeed there is some evidence that a greater use of the Internet and eshopping online is also associated with more shopping trips.

Robyn Dowling focuses on automobilities and travel with children, perceiving the private motor car as a 'daily management' tool, an important facilitator in managing family life, and deeply associated with aspirations for and relationships with children. The car is used to facilitate 'good parenting', particularly during the school run, with the car used to access educational and other activities, and enable busy schedules. The time in the car is often seen as family time. Much of this discussion perhaps reflects the Australian context which is reported on, where there is often little alternative to the car to access activities. The 
objective of good mothering is so highly valued by some respondents that many were willing to make considerable sacrifices for its achievement, including, for example, overlooking any disenchantment with driving as an activity.

Randi Hjorthol and Susanne Nordbakke take a different angle, assessing car driving patterns amongst the older population, including the often critical role of the car in accessing everyday activities. Using National Travel Survey cohort data from Norway, Denmark and Sweden, they focus on lifecycle changes and find that the growth in the elderly population will influence mobility patterns in Europe considerably. They use indepth interviews and surveys to further examine the perceived utility of the car for older people, asking whether use of the car contributes to well-being and whether the car/ability to drive has an impact on participation in activities that generate well-being. For example, the loss of the use of the car in later life often leads to reductions in freedom, independence, pleasure of driving and control of life.

Gamze Dane, Anna Grigolon, Soora Rasouli, Harry Timmermans and Dujuan Yang explore activity participation, vacations, travel behaviours and travel expenditures of the elderly in the Netherlands. The analyses suggest that the elderly (over 65 years of age) have less 'compulsory' activity-travel behaviour (i.e. working), though for maintenance and leisure activities, both travel time and travel distances are slightly higher than the overall average. Travel time and travel distance of ageing people by car is higher for compulsory activities, but these mobility indicators decrease rapidly with increasing age. The start time of activities of the ageing population is later than average, except for maintenance activities. Hence, as constraints and commitments are relaxed (such as travelling to work), activity-travel patterns become more flexible and tend to shift to off-peak hours.

Jago Dodson, Neil Sipe and Terry Li explore the problem of combined volatile oil prices and housing mortgage cost pressures within a large, dispersed city region, using Brisbane, Australia, as a case study. The problem of 'oil vulnerability' is examined, i.e. the socioeconomic exposure of households to rising oil and motor vehicle fuel prices, based on their socio-economic status, car-dependence and access to alternative modes. Using two indices of vulnerability (VIPER and VAMPIRE), the distributional impact of higher oil prices is shown to be greater for lower income households, with high levels of car dependence and relatively poorer access to alternative travel modes such as public transport - and often these households are concentrated in the suburbs.

Erling Holden and Kristin Linnerud explore the difficult problem that sustainable passenger transport policies are most often directed towards everyday travel, but ignore the large and expanding amount of leisure travel. They examine whether policies aimed at reducing energy consumption and CO2 emissions for everyday travel may have an opposite effect on leisure travel by assessing the impacts of three sustainable passenger transport policies: developing more compact cities, building pro-environment awareness and attitudes, and promoting the growth of information and communication technologies. It is found that the policies used may indeed have unintended effects. Several mechanisms, such as moral accounting, are suggested that might explain why this occurs. The potential for developing more comprehensive sustainable transport policies is also considered, including limiting densification policies and improving environmental awareness amongst the population. 
Mayer Hillman reminds us that the spreading and intensifying addiction to fossil fueldependent lifestyles around the world will inevitably lead to huge ecological problems from climate change. Current policymaking and patterns of development will not deliver the very low-carbon footprints essential to preventing such problems. It is argued that a large scale programme to educate the public on the links between energy-intensive lifestyles and carbon emissions is required, alongside the introduction of personal carbon allowances, and a cap on aggregate emissions - the latter shared equally on a per capita basis globally, and following contraction and convergence principles. Finally, that all of us have a responsibility to make the necessary changes to our lifestyles to limit the impacts of climate change on the planet. In particular, professions such as transport and urban planning, have a critical role to play.

Harry Geerlings and Flor Avelino examine the role of transition management, as a new mode of governance which may help move towards sustainable development, involving a transformation process in which society changes in a fundamental way over a generation or more. A case study from the Dutch transport sector is used: the Transumo A15-Maasvlakte sustainable freight project. The multi-level perspective is employed, including the different scales of landscape (macro-level), regime (meso-level) and niche (micro-level). Consideration is given to understanding the likely 'frontrunners': individuals that are 'ahead' with developing new structures, cultures, and practices in sustainable transport and then to scaling these up wherever this is possible. The case study demonstrates the difficulty that many important stakeholders seem to be locked into conventional visions on port and business development, and that it is difficult to find leaders of change in such contexts.

Helmut Holzapfel and Rainer Meyfahrt examine the renaissance of the regional tram-train system in Kassel, Germany, and in particular consider the importance of strong regional government in delivery. Responsibility for planning, the fare system, and the design of transport schemes was transferred to regional institutions from the 1970s onwards in Kassel, and the RegioTram was gradually expanded and enhanced. The process however was difficult, involving the coordination of many different interests within local, regional, national and transnational institutions, including with Deutsche Bahn. The investment has had a large impact on the redevelopment of central Kassel and the wider region strengthening the functions of the central city (including education, administration, higher order shopping) and promoted accessibility to the smaller municipalities throughout the region.

Dominic Stead discusses the development of transport policy at the European Union level, from the 1950s to the present date. There have been a number of Treaties (Paris, Rome, Amsterdam, Lisbon) and attempts to develop a common European Transport Policy, but this been difficult to agree at the national level, with many different perspectives, priorities and interests proving impossible to bring together. Key dilemmas are discussed within European transport policy, such as the reconciliation of the free movement of people and goods, one of the one of basic pillars of the European Union, while at the same time protecting the environment and improving the health and safety of citizens. Major initiatives and investments, such as the liberalisation of transport markets and investment in the Trans-European Transport Network, are highlighted as emerging from lobbying efforts 
from industry organisations, often with little regard for sustainability ambitions, and leading to a major focus on road building.

Tim Schwanen brings Part IV to a close in assessing the practice of transport research in terms of the dynamics of relationships. Reflecting on the philosophy of Alfred Whitehead, it is argued that understanding temporality is critical to research on transport and development. The conventional practice of drawing inferences from cross-sectional data is often problematic, with assumptions made on relationships staying current or changing in a linear fashion, replicating closed systems, with very simple cause and effect relationships and often leading to the 'fallacy of misplaced concreteness'. For example, understanding the use of a car, the competency required for cycling, a pro-environmental attitude, or the environmental, social or economic impacts of investment, cannot be assigned to a specifiable point in space and time. This critiques much of the previous research in this area, for these are the assumptions that are made in much of the work, and there are important implications that lead from this. However, a direction forward for research is also offered: exploring process, and the different ways of understanding this, might help us to develop a deeper understanding of the transport and development field in future years.

\section{Part V: Summary and conclusions}

In Part V, the final chapter brings the edited collection to a close, attempting to synthesise a very wide-ranging field, including the changes experienced in urban development - in retrospect and also in prospect. Comments are made on the development of the research field in transport and development over the last 30 years, and the potential avenues forward.

This edited book hence forms an extensive review of the debate surrounding the transport and development topic - we are delighted to have assembled such a fine collection of authors, and we think this is a remarkable collection of different, often competing, viewpoints - which sit happily side-by-side, competing for attention. We have journeyed a long way in understanding how urban development might interact with travel, and how transport might interact with urban development - and the varied forms in between. We hope you enjoy the debate, and of course you can decide which you agree with, to what extent, and for how long - before you modify your views.

\section{References}

Miller, A. (1949) Death of a Salesman. London, Penguin Books (Penguin Classics, 2000). 